
pathogenesis of SLE: a new look at an old paradigm

\author{
David Pisetsky
}

To cite: Pisetsky D. The role of microparticles in the pathogenesis of SLE: a new look at an old paradigm. Lupus Science \& Medicine 2017;4:e000220. doi:10.1136/ lupus-2017-000220

Received 11 April 2017 Accepted 12 April 2017

CrossMark

Department of Rheumatology and Immunology, Duke University Medical Center, Durham, North Carolina, USA

Correspondence to
Winberg et al $^{1}$ present important new information on a story that began with the discovery of the lupus erythematosus (LE) cell phenomenon. As described in a truly landmark paper, Hargraves and colleagues established the existence of the LE cell phenomenon using bone marrow specimens from patients with SLE. The LE cell reflects the unique immune environment in SLE and is basically a cell nucleus that has been opsonised by an ANA and complement and is then engulfed by a neutrophil. ${ }^{2}$ The key players for this phenomenon (nucleus, ANA, complement, phagocyte) remain at the centre of lupus research today, a rare example of a paradigm that has barely shifted or wobbled during the course of many decades.

In the study of the LE cell, the nucleus has received much less attention than the other players which, after all, are usual blood components. In ordinary circumstances, the nucleus resides within the safe confines of the cell; with the exception of physiological enucleation during red blood cell maturation, nuclei do not transit into the extracellular milieu. In contrast, nuclear material including chromatin and its DNA and histone components can readily leave cells during the pounding and crushing of cells as they die. ${ }^{3}$ In the current model of lupus pathogenesis, excessive cell death or insufficient dead cell clearance leads to a large flux of nuclear material into the blood to form immune complexes (ICs) or drive autoreactivity. ${ }^{4}$

Despite much peering into microscopes, investigators have produced little decisive evidence for the extracellular translocation of nuclei during cell death. Studies indicate that nuclear material rather than exiting the cell as an intact nucleus, undergoes relocation, rearrangement and repackaging to form apoptotic bodies and microparticles. An apoptotic body is the collapsed remnant of an apoptotic cell or a large fragment that has broken off as apoptotic shrinkage occurs.
An apoptotic body can be relatively large (up to $3 \mu$ in diameter). On morphological grounds, it can be difficult to distinguish an apoptotic body from a nucleus, although the DNA content of an apoptotic body should be much less because of the extensive cleavage of DNA during apoptosis. ${ }^{56}$

In contrast to apoptotic bodies, microparticles (MPs) are small membrane vesicles, usually $0.1-1.0 \mu$ in diameter that detach from apoptotic cells, possibly originating as blebs; MPs can also arise from activated cells, especially platelets, and platelet MPs are the most abundant in the blood. ${ }^{5}{ }^{6}$ MPs constitute a major class of vesicles in the blood and contain an ensemble of cellular constituents whose composition may vary depending on the cell of origin. Importantly, MPs from nucleated cells contain chromatin in a form that can react with anti-DNA and other antinucleosomal antibodies to form ICs. These complexes can contribute to lupus pathogenesis by depositing in the tissue, especially the kidney to induce nephritis. ${ }^{7}$ Following uptake by dendritic and phagocytic cells, the DNA in these complexes can stimulate cytokine production by interaction with tolllike receptor (TLR) and non-TLR internal nucleic acid sensors. In addition, MPs have direct proinflammatory and prothrombotic properties that can impact on disease. The table highlights some key features of MPs.

While Winberg et al do not invoke the LE cell as an inspiration for their work, their study describes a similar scenario, with MPs sharing the same fate as a nucleus: phagocytosis after opsonisation. In initial studies using flow cytometry, these investigators explored the blood 'particulome' and show that particle numbers in samples from patients with lupus are similar to those of healthy controls. The MPs from patients with lupus, however, had an increased proportion with bound C3d, although a decrease in the amount of C3b and iC3b; this decrease could limit phagocytosis. 
Furthermore, Winberg et al showed that MPs from both lupus and healthy controls can be bound by monocytes and granulocytes in vitro, with inhibition by red blood cells suggesting buffering in the blood by this cellular component.

Although the observed differences on levels of complement component on the MPs are not large, the authors nevertheless suggest that their data are consistent with the prevailing view that lupus is associated with impaired clearance of dead and dying cells and their remains, in this case, MPs. This conclusion bears some consideration in view of data from other studies on MP numbers in patients with lupus. As the authors note, studies have differed on particle numbers in lupus blood. ${ }^{8-10}$ An increase in numbers would be predicted if clearance is impaired. However, levels in lupus blood may be comparable to those in healthy controls if an increase in MPs from impaired clearance would be balanced by increased tissue deposition. Winberg et al advance this explanation to account for the lack of a significant difference between particle numbers in lupus and healthy control blood.

Methodological issues may also account for variations in the number of MPs observed in blood in different studies. Assay of MPs by flow cytometry is notoriously difficult, related to factors such as sample handling (eg, effects of storage and centrifugation), gating strategy and instrument sensitivity. Many instruments cannot detect particles smaller in size than $0.3-0.5 \mu$. Furthermore, as this study shows, the range in MP numbers in blood samples is extensive. These considerations suggest that a large number of patient samples is needed to assess reliably the number of MPs in the circulation and therefore explore any lesions in the operation of clearance systems.

Another limitation of this study relates to the lack of detailed serological data to interpret bound complement components. As now demonstrated in several studies, ANAs bind particles generated in vitro; furthermore, particles obtained from lupus blood have increased levels of bound IgG. ${ }^{8-11}$ The study by Winberg et al looked only at complement products and not at IgG. In the absence of data on particle IgG and the capacity of sera to bind to particles, it is difficult to know whether the presence of complement on MPs results from fixation by IgG. In this regard, the levels of bound complement component on MPs from patients with lupus and healthy controls were, in general, similar, making an effect on particle clearance in lupus uncertain.

A related issue concerns the DNA content of MPs and its status in an immunological accessible form. The presence of this DNA can be conveniently determined by fluorescent dyes that can bind DNA. ${ }^{12}$ These dyes include SYTO 13 which can penetrate intact membranes and bind DNA in or on particles. Dyes such as propidium iodide or 7-aminoactinomycin (7-AAD) do not enter cells (or particles) with intact membranes, leading to their utility to assess cell necrosis because of the breach of permeability barriers. In the supplemental table, the authors indicate that only a minority of MPs bind 7-AAD. These results are surprising, although it could reflect the methodology used. A more extensive analysis of the nucleic acid content of the MPs would, therefore, be important.

The role of DNA-rich extracellular organelles (ie, MPs, apoptotic bodies and mitochondria) is now a hot topic, with recent studies stoking interest in the role of nucleases in determining the pathogenicity of MPs. A recent study has provided intriguing evidence for the role of an exonuclease called DNase 1-like 3 (DNase 1L3) in the generation extracellular DNA in the form of particles in lupus. DNase 1L3 digests DNA in the form of nucleosomes in contrast to DNase 1 which has a preference for free DNA. Furthermore, in contrast to DNase 1, DNase 1L3 has a highly basic C-terminus which allows it to penetrate certain vesicular or membranous structures; this enzyme, therefore, may be particularly active in digesting DNA in MPs. ${ }^{13}$ In humans, mutations in DNase 1L3 lead to a vasculitic condition with features of lupus while, in mice, a gene knockout for this enzyme promotes a lupuslike condition in which the DNA content of MPs rises dramatically. ${ }^{14-16}$ Because immunisation of normal mice with MPs from the knockout mice can induce anti-DNA production (although in the presence of interferon), a role of particles in ANA induction is suggested. ${ }^{16}$

As these considerations indicate, the study of Winberg et al, along with the work of others on MPs, reprise themes established for the LE cell so much that one wonders whether the engulfed nucleus in the classical assay of LE cells is an apoptotic body or a large MP rather than an errant or rogue nucleus. The evidence for a role of MPs in lupus is growing and perhaps it is reasonable to consider lupus as a disease of aberrant particle biology. While 'particulopathy' is not a very euphonious word, it does convey the diverse roles MPs can play in disease pathogenesis and how small structures can have a big impact on autoimmunity.

\section{PROPERTIES OF MICROPARTICLES}

- 0.1-1.0 in diameter

- Detected by flow cytometry using sized beads to establish windows

- Promote inflammation and thrombosis

- Derived from dead and dying cells as blebs

- Bear cell surface markers from cell of origin

- Contain nuclear autoantigens to form immune complexes with anti-DNA and other ANA

Competing interests None declared.

Provenance and peer review Commissioned; internally peer reviewed.

Open Access This is an Open Access article distributed in accordance with the Creative Commons Attribution Non Commercial (CC BY-NC 4.0) license, which permits others to distribute, remix, adapt, build upon this work non-commercially, and license their derivative works on different terms, provided the original work is properly cited and the use is non-commercial. See: http://creativecommons.org/ licenses/by-nc/4.0/

(C) Article author(s) (or their employer(s) unless otherwise stated in the text of the article) 2017. All rights reserved. No commercial use is permitted unless otherwise expressly granted. 


\section{REFERENCES}

1. Winberg LK, Nielsen $\mathrm{CH}$, Jacobsen S. Surface complement $\mathrm{C} 3$ fragments and cellular binding of microparticles in patients with systemic lupus erythematous. Lupus Sci Med 2017;4:e000193.

2. Hepburn AL. The LE cell. Rheumatology 2001;40:826-7.

3. Pisetsky DS. The translocation of nuclear molecules during inflammation and cell death. Antioxid Redox Signal 2014;20:1117-25.

4. Mahajan A, Herrmann M, Muñoz LE. Clearance Deficiency and Cell Death Pathways: a Model for the pathogenesis of SLE. Front Immunol 2016;7:35.

5. Pisetsky DS, Ullal AJ, Gauley J, et al. Microparticles as mediators and biomarkers of rheumatic disease. Rheumatology 2012;51:1737-46.

6. Buzas El, György B, Nagy G, et al. Emerging role of extracellular vesicles in inflammatory diseases. Nat Rev Rheumatol 2014;10:356-64.

7. Nielsen CT, Østergaard O, Rekvig OP, et al. Galectin-3 binding protein links circulating microparticles with Electron dense glomerular deposits in lupus nephritis. Lupus 2015;24:1150-60.

8. Nielsen CT, Østergaard O, Stener L, et al. Increased IgG on cellderived plasma microparticles in systemic lupus erythematosus is associated with autoantibodies and complement activation. Arthritis Rheum 2012;64:1227-36.
9. Fortin PR, Cloutier N, Bissonnette V, et al. Distinct subtypes of Microparticle-containing immune complexes are associated with disease activity, damage, and carotid Intima-media thickness in systemic lupus erythematosus. J Rheumatol 2016;43:2019-25.

10. Mobarrez F, Vikerfors A, Gustafsson JT, et al. Microparticles in the blood of patients with systemic lupus erythematosus (SLE): phenotypic characterization and clinical associations. Sci Rep 2016;6:36025.

11. Ullal AJ, Reich CF, Clowse M, et al. Microparticles as antigenic targets of antibodies to DNA and nucleosomes in systemic lupus erythematosus. J Autoimmun 2011;36:173-80.

12. Ullal AJ, Pisetsky DS, Reich CF. Use of SYTO 13, a fluorescent dye binding nucleic acids, for the detection of microparticles in in vitro systems. Cytometry A 2010;77:294-301.

13. Wilber A, Lu M, Schneider MC. Deoxyribonuclease I-like III is an inducible macrophage barrier to liposomal transfection. Mol Ther 2002;6:35-42.

14. Al-Mayouf SM, Sunker A, Abdwani R, et al. Loss-of-function variant in DNASE1L3 causes a familial form of systemic lupus erythematosus. Nat Genet 2011;43:1186-8.

15. Ozçakar ZB, Foster J, Diaz-Horta O, et al. DNASE1L3 mutations in hypocomplementemic urticarial vasculitis syndrome. Arthritis Rheum 2013;65:2183-9.

16. Sisirak V, Sally B, D'Agati V, et al. Digestion of chromatin in apoptotic cell Microparticles prevents autoimmunity. Cell 2016;166:88-101. 